\title{
A Survey of the Use of Perioperative Glucocorticoids in Oral and Maxillofacial Surgery
}

\section{Kormi, Eeva}

2016-08

Kormi , E , Snall , J , Tornwall , J \& Thoren , H 2016 , ' A Survey of the Use of Perioperative Glucocorticoids in Oral and Maxillofacial Surgery ' , Journal of Oral and Maxillofacial Surgery , vol. 74 , no. 8 , pp. 1548-1551 . https://doi.org/10.1016/j.joms.2016.02.027

http://hdl.handle.net/10138/224121

https://doi.org/10.1016/j.joms.2016.02.027

publishedVersion

Downloaded from Helda, University of Helsinki institutional repository.

This is an electronic reprint of the original article.

This reprint may differ from the original in pagination and typographic detail.

Please cite the original version. 


\title{
A Survey of the Use of Perioperative Glucocorticoids in Oral and Maxillofacial Surgery
}

\author{
Eeva Kormi, DDS, MD, *Johanna Snäll, DDS, $M D, P b D, \dagger$ \\ Jyrki Törnwall, DDS, MD, PbD, $\ddagger$ and Hanna Thorén, $D D S, M D, P b D \S$
}

Purpose: The aim of the study was to clarify the use of perioperative glucocorticoids (GCs) in association with oral and maxillofacial surgical procedures.

Materials and Methods: We conducted a survey of consultant oral and maxillofacial surgeons (OMSs) working in tertiary and secondary referral hospitals in Finland.

Results: The administration of GCs is common among OMSs ( $85.2 \%$ of respondents), especially in association with orthognathic surgery (100\% of respondents) and facial fractures (43.5\%). All OMSs who administered GCs reported that they reduce swelling. The next most common reasons for administering GCs were established practice (43.5\%) and pain reduction (39.1\%). The regimens differed widely from a 5-mg single dose to a 116-mg total dose of dexamethasone equivalent.

Conclusions: GCs are widely administered by OMSs, especially in major surgery. The literature shows some benefits of their use in dental and orthognathic operations, and their use seems rather safe. Proof of efficacy remains to be determined for other major maxillofacial surgical procedures; thus further studies are needed.

(C) 2016 American Association of Oral and Maxillofacial Surgeons

J Oral Maxillofac Surg 74:1548-1551, 2016

Glucocorticoids (GCs) are involved in a wide variety of homeostatic, cardiovascular, metabolic, and immunologic actions. The natural GC cortisol is produced in the adrenal cortex and controlled by the hypothalamus and anterior pituitary gland. The synthetic GCs mimic the effects of cortisol, but have different biological half-lives and potencies.

GCs have been reported in the literature to be beneficial in reducing postoperative inflammatory symptoms in patients undergoing surgical removal of the third molar. ${ }^{1-13}$ Studies also have shown that patients undergoing orthognathic surgery may benefit from GCs. ${ }^{14,15}$ However, the effect on surgical wound healing is contradictory. ${ }^{16-18}$ After surgery for orbital blowout fractures, GCs improve interpalpebral width. ${ }^{19}$ In reconstructive surgery, to our knowledge,

Received from Department of Oral and Maxillofacial Diseases, University of Helsinki and Helsinki University Hospital, Helsinki, Finland.

*Resident.

$\dagger$ Resident.

$\ddagger$ Head of Department.

$\S$ Consultant and Senior Lecturer.

Address correspondence and reprint requests to Dr Kormi: Department of Oral and Maxillofacial Diseases, Helsinki University the evidence on GCs is nonexistent. Yet, because of their immunosuppressive effects, GCs are probably widely used in association with various types of surgical procedures in the facial region.

Assimes and Lessard ${ }^{20}$ conducted a survey of North American members of the American Society of Maxillofacial Surgeons to clarify the prevalence of administration of GCs by surgeons performing craniomaxillofacial or esthetic surgery. The survey showed that $46.7 \%$ of the respondents administer short-term high-dose GCs perioperatively. This finding reflects our experience that GCs also are used frequently in Finland, but it remains unclear why, when, and how they are used.

The aim of this study was to clarify the use of perioperative GCs in association with oral and maxillofacial surgical procedures. The specific aim was to design 
and implement a survey of Finnish consultant oral and maxillofacial surgeons (OMSs) working in secondary and tertiary referral hospitals to identify the prevalence of, and reasons for, administering GCs. The main hypothesis was that GCs are commonly administered to decrease postoperative swelling and pain.

\section{Materials and Methods}

All oral and maxillofacial consultants in 12 secondary and 5 tertiary referral hospitals in Finland were contacted by phone or in person and asked to respond to a standardized questionnaire about their policy for administration of short-term high-dose perioperative GCs. The inclusion criterion was that the respondent performs 1 or more of the surveyed surgical procedures on a regular basis. Of 34 consultants contacted, $27(79.4 \%)$ responded to the questionnaire.

The key question was "Do you use short-term highdose perioperative GCs in association with oral and maxillofacial surgery?" Use of GCs as a substitute for any medical condition was excluded.

The respondents who do not administer GCs were further asked to specify the reasons for not administering corticosteroids. The options were as follows: 1) the literature does not support the use of GCs, 2) there is an increased risk of complications, 3) GCs are not cost-effective, 4) GCs offer no benefits, and/ or 5) other reason (with a request to elaborate).

The OMSs who administer GCs were further asked about their reason for use, among several options: 1) reduces swelling (airway compromise or general swelling caused by surgery was not further defined), 2) reduces pain, 3) reduces postanesthesia nausea, 4) improves operation outcome in general, 5) shortens hospitalization time, 6) shortens sick leave, 7) is an established practice of our department, and/ or 8 ) other reason (with a request to elaborate). These OMSs also were asked to report any steroid-induced complications that they had encountered.

Finally, the steroid-administering consultants were asked about their frequency of GC administration in patients undergoing third molar surgery or dentoalveolar surgery, orthognathic surgery, surgery for facial fractures, and oncologic reconstructive surgery. The options were 1) always or very often, 2) about half of the cases, 3) seldom, or 4) I do not perform this kind of surgery. The participants also were asked to provide detailed information about their treatment regimens for each of the aforementioned procedures.

\section{Results}

Of the 27 respondents, 7 held double degrees (ie, MD and DDS) and all of them claimed they administer GCs. Years in practice did not seem to reflect the policy regarding the administration of GCs, nor did the place of work (ie, tertiary or secondary referral hospital) (Table 1).

\section{RESPONDENTS ADMINISTERING GCS}

Of the 27 respondents, $23(85.2 \%)$ claimed that they administer perioperative GCs. The reasons for GC administration were many. All 23 OMSs who administer GCs agreed that they reduce swelling. The additional reasons for GC administration were as follows: it is an established practice of the department (10 of 23 OMSs who administer GCs, 43.5\%), it reduces pain ( 9 of $23,39.1 \%)$, it shortens hospitalization time ( 7 of $23,30.4 \%$ ), it reduces postanesthesia nausea ( 4 of $23,17.4 \%$ ), and it shortens sick leave ( 1 of $23,4.3 \%$ ).

Of those respondents who perform orthognathic surgery actively, $100 \%$ claimed that they administer GCs, the respective figures for those who perform reconstructive surgery, facial fracture surgery, and third molar or dentoalveolar surgery being $50.0 \%$, $43.5 \%$, and $3.7 \%$. Figure 1 shows the frequencies of GC administration in more detail, in association with different types of surgical procedures.

The steroid regimens differed greatly between the respondents in general and were particularly different between types of procedures. Overall, dexamethasone was the most frequently used GC, being administered by 13 respondents (60.9\%). Hydrocortisone ( 6 respondents, 26.1\%) and methylprednisolone (5 respondents, $21.7 \%$ ) also were occasionally used.

Some respondents initiated treatment on the evening before surgery, whereas others initiated it during induction of anesthesia or intraoperatively. The course

Table 1. RESPONDENTS' BACKGROUND

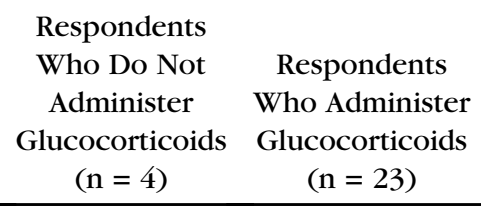

\begin{tabular}{|c|c|c|}
\hline \multicolumn{3}{|l|}{ Experience } \\
\hline $6-10 \mathrm{yr}$ & - & 5 \\
\hline $11-15 \mathrm{yr}$ & 1 & 5 \\
\hline $15-20 \mathrm{yr}$ & - & 4 \\
\hline$\geq 20 \mathrm{yr}$ & 3 & 9 \\
\hline \multicolumn{3}{|l|}{ Working hospital } \\
\hline Secondary & 1 & $11^{*}$ \\
\hline Tertiary & 3 & $13^{*}$ \\
\hline \multicolumn{3}{|l|}{ Degrees } \\
\hline Double (MD, DDS) & - & 7 \\
\hline Single (DDS) & 4 & 16 \\
\hline
\end{tabular}

* One surgeon working in 2 hospitals.

Kormi et al. Use of Perioperative Glucocorticoids. J Oral Maxillofac Surg 2016. 


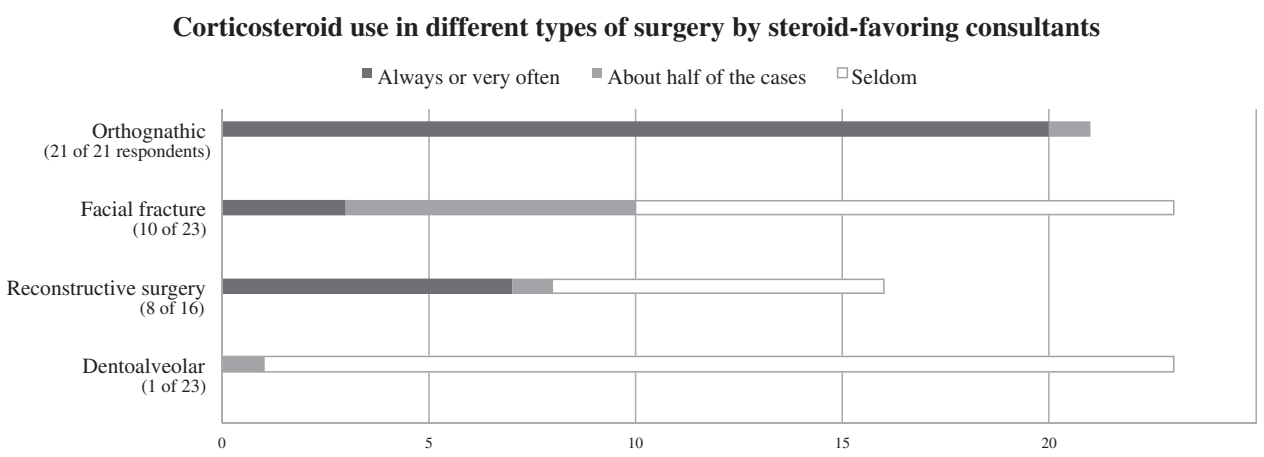

FIGURE 1. Corticosteroid use in different types of surgery by steroid-favoring consultants.

Kormi et al. Use of Perioperative Glucocorticoids. J Oral Maxillofac Surg 2016.

length ranged from a single dose of GC to a perioperative course lasting up to 4 days postoperatively. Doses varied from a single dose of $5 \mathrm{mg}$ to a total dose of $116 \mathrm{mg}$ of dexamethasone equivalent. The total dose of GC in association with orthognathic surgery, facial trauma surgery, and reconstructive surgery was most often 10 to $40 \mathrm{mg}$ of dexamethasone equivalent. Those OMSs preferring higher total doses preferred longer courses as well. Only 1 of the OMSs who administer GCs (4.3\%) had encountered GC-related complications: these related to muscular pain in some patients who had been given the medication intramuscularly.

\section{RESPONDENTS NOT ADMINISTERING GCS}

Of the 4 respondents who claimed that they do not administer GCs, 2 were of the opinion that they are not cost-effective and the other 2 saw no benefits whatsoever in administering them.

\section{Discussion}

This study presents our survey results regarding the prevalence of, and reasons for, GC administration by Finnish consultant OMSs working in secondary and tertiary referral hospitals. The main hypothesis was that GCs are commonly administered to decrease postoperative swelling and pain.

An interesting finding was that 2 respondents claimed that the use of GCs is too costly, given that the price seems rather negligible (eg, US \$6.11 for dexamethasone, $5 \mathrm{mg}$ intravenously). The results showed that the great majority of the respondents (85.2\%) administer GCs. The main medical reasons for administering GCs were that they reduce postoperative swelling (claimed by $100 \%$ of the OMSs who administer GCs) and pain (39.1\%). An established practice of one's department is considered a recommendation, but consultants are autonomous and may decide not to follow the policy of the hospital. However, because many consultants (43.5\%) base their administration of GCs on this, it seems that, in many hospitals, the use is recommended, and this is considered justified by the surgeons.

The use of GCs most likely stems from numerous studies supporting their use in third molar surgery. ${ }^{1-13}$ Parallel to the respondents' reasoning for administering GCs, these studies also show reduced postoperative pain and edema. Interestingly, despite support by the literature, GC use was rare in Finnish third molar surgical procedures. The reason for this may be that third molar surgery is considered minor and procedures are mainly performed in outpatient departments with patients under local anesthesia only. In orthognathic surgery, on the other hand, GC use was a widely established practice; $100 \%$ of consultants performing orthognathic surgical procedures actively administer GCs.

Weber and Griffin ${ }^{14}$ randomly assigned a total of 23 patients undergoing orthognathic surgery to 1 of 3 groups, with all patients receiving 1 preoperative infusion and 3 postoperative infusions every 6 hours. Seven patients received placebo, eight received $16 \mathrm{mg}$ of dexamethasone preoperatively and 3 doses of placebo postoperatively, and eight received $16 \mathrm{mg}$ of dexamethasone preoperatively and three 8-mg doses postoperatively. The results showed that preoperative intravenous dexamethasone reduced postoperative inflammation and its associated edema significantly. Parallel results were observed by Schaberg et $\mathrm{al}^{15}$ with the use of methylprednisolone. The policy of administering perioperative GCs in association with orthognathic surgery seems justified.

In our study, half of the respondents who perform reconstructive surgery, as well as $43.5 \%$ of those who treat facial fractures, claimed to administer GCs. Little has been published about the benefits of GCs in such procedures; however, the exception is the study by Flood et $\mathrm{al}^{19}$ that focused on orbital floor fractures. They randomly allocated 20 patients to receive methylprednisolone, $250 \mathrm{mg}$ intravenously, at induction of anesthesia, followed by a further 3 doses at 6-hour intervals, or alternatively to receive placebo, 
which was given with the same frequency. Patients who received GCs had a statistically significant increase in interpalpebral width. The authors concluded that courses of steroid therapy should be considered in orbital surgery for appropriate patients because of an advantage in being able to assess the globe postoperatively. It should be noted that in Finland, neurosurgeons are responsible for the treatment of skull base fractures and elevated intracranial pressure, and thus these conditions were not included in this query. In addition, ophthalmologists are often consulted regarding trauma to the eye adnexa and nerves, and the use of GCs may be directed by them.

Although most steroid-related complications occur after long-term use, severe complications also have been reported in association with short-term highdose treatment. Fleming and Flood ${ }^{21}$ described steroid-induced psychosis in a 16 -year-old previously healthy female patient who received a regimen of $250 \mathrm{mg}$ of methylprednisolone intravenously at induction, followed by 3 further doses of $250 \mathrm{mg}$ at 6-hour intervals, in association with orthognathic surgery. The influence on surgical wound healing is contradictory. ${ }^{16-18}$ Although none of the respondents in our study had encountered any severe complications, the potential adverse effects of steroids in general, and contraindications for their use in particular, clearly must be recognized. For further information about contraindications and systemic side effects, the reader is referred to the comprehensive literature review about perioperative corticosteroid use in dentoalveolar surgery by Alexander and Throndson. ${ }^{22}$

The perioperative GC regimens used by the respondents in our study varied greatly. The variation is understandable because different types of procedures were included in the survey. In addition, no general recommendations exist. In general, the use of shortterm GCs seems to be rather safe, and Finnish consultants had not encountered severe complications. However, several questions remain open: When should treatment be initiated? What should the single doses, dose frequencies, and total dose be? How long should the treatment last? Which regimens are effective but do not increase steroid-related complications?

The wide use of GCs in oral and maxillofacial surgery, as well as the variety of regimens used, indicates the need for further clinical studies on their effects, especially in major surgical procedures. In particular, the benefits of GC use in reconstructive and facial trauma surgery are yet to be studied.

\section{References}

1. Schmelzeisen R, Frölich JC: Prevention of postoperative swelling and pain by dexamethasone after operative removal of impacted third molar teeth. Eur J Clin Pharmacol 44:275, 1993

2. Grossi GB, Maiorana C, Garramone RA, et al: Effect of submucosal injection of dexamethasone on postoperative discomfort after third molar surgery: A prospective study. J Oral Maxillofac Surg 65:2218, 2007

3. Bamgbose BO, Akinwande JA, Adeyemo WL, et al: Effects of coadministered dexamethasone and diclofenac potassium on pain, swelling and trismus following third molar surgery. Head Face Med 1:11, 2005

4. Beirne OR, Hollander B: The effect of methylprednisolone on pain, trismus, and swelling after removal of third molars. Oral Surg Oral Med Oral Pathol 61:134, 1986

5. Hooley JR, Francis FJ: Betamethasone in traumatic oral surgery. J Oral Surg 27:398, 1969

6. Huffman GG: Use of methylprednisolone sodium succinate to reduce postoperative edema after removal of impacted third molars. J Oral Surg 35:198, 1977

7. Hyrkäs T, Ylipaavalniemi P, Oikarinen VJ, Paakkari I: A comparison of diclofenac with and without single-dose intravenous steroid to prevent postoperative pain after third molar removal. J Oral Maxillofac Surg 51:634, 1993

8. Milles M, Desjardins PJ: Reduction of postoperative facial swelling by low-dose methylprednisolone: An experimental study. J Oral Maxillofac Surg 51:987, 1993

9. Messer EJ, Keller JJ: The use of intraoral dexamethasone after extraction of mandibular third molars. Oral Surg Oral Med Oral Pathol 40:594, 1975

10. Skjelbred P, Lokken P: Post-operative pain and inflammatory reaction reduced by injection of a corticosteroid. A controlled trial in bilateral oral surgery. Eur J Clin Pharmacol 21:391, 1982

11. Skjelbred P, Lokken P: Reduction of pain and swelling by a corticosteroid injected 3 hours after surgery. Eur J Clin Pharmacol 23: 141,1982

12. Neupert EA III, Lee JW, Philput CB, Gordon JR: Evaluation of dexamethasone for reduction of postsurgical sequelae of third molar removal. J Oral Maxillofac Surg 50:1177, 1992

13. Antunes AA, Avelar RL, Martins Neto EC, et al: Effect of two routes of administration of dexamethasone on pain, edema, and trismus in impacted lower third molar surgery. Oral Maxillofac Surg 15:217, 2011

14. Weber CR, Griffin JM: Evaluation of dexamethasone for reducing postoperative edema and inflammatory response after orthognathic surgery. J Oral Maxillofac Surg 52:35, 1994

15. Schaberg SJ, Stuller CB, Edwards SM: Effect of methylprednisolone on swelling after orthognathic surgery. J Oral Maxillofac Surg 42:356, 1984

16. Snäll J, Kormi E, Koivusalo AM, et al: Effects of perioperatively administered dexamethasone on surgical wound healing in patients undergoing surgery for zygomatic fracture: A prospective study. Oral Surg Oral Med Oral Pathol Oral Radiol $117: 685,2014$

17. Snäll J, Kormi E, Lindqvist C, et al: Impairment of wound healing after operative treatment of mandibular fractures, and the influence of dexamethasone. $\mathrm{Br} \mathrm{J}$ Oral Maxillofac Surg 51:808, 2013

18. Waldron NH, Jones CA, Gan TJ, et al: Impact of perioperative dexamethasone on postoperative analgesia and side-effects: Systematic review and meta-analysis. Br J Anaesth 110:191, 2013

19. Flood TR, McManners J, el-Attar A, Moos KF: Randomized prospective study of the influence of steroids on postoperative eye-opening after exploration of the orbital floor. $\mathrm{Br} \mathrm{J}$ Oral Maxillofac Surg 37:312, 1999

20. Assimes T, Lessard ML: The use of perioperative corticosteroids in craniomaxillofacial surgery. Plast Reconstr Surg 103:313, 1999

21. Fleming PS, Flood TR: Steroid-induced psychosis complicating orthognathic surgery: A case report. Br Dent J 199:647, 2005

22. Alexander RE, Throndson RR: A review of perioperative corticosteroid use in dentoalveolar surgery. Oral Surg Oral Med Oral Pathol Oral Radiol Endod 90:406, 2000 